\title{
DETERIORATION OF BLEACHABILITY INDEX PADA CRUDE PALM OIL: BAHAN REVIEW DAN USULAN UNTUK SNI 01-2901-2006 Deterioration of Bleachability Index of Crude Palm Oil: Review Material and Recommendation for SNI 01-2901-2006
}

\author{
Hasrul Abdi Hasibuan \\ Pusat Penelitian Kelapa Sawit, JI. Brigjend Katamso No. 51 Medan, Sumatera Utara, Indonesia \\ Email: hasibuan_abdi@yahoo.com
}

Diterima: 30 Juli 2015, Direvisi: 23 Maret 2016, Disetujui: 23 Maret 2016

\begin{abstract}
Abstrak
Standar mutu Crude Palm Oil (CPO) dalam SNI 01-2901-2006 adalah kadar asam lemak bebas (ALB), air dan kotoran masing-masing maksimum $5 \%, 0,25 \%$ dan $0,25 \%$. Parameter lain yang dapat menentukan mutu CPO adalah deterioration of bleachability index (DOBI) namun belum ditetapkan dalam SNI CPO. Sementara itu, beberapa industri rafinasi di dalam negeri dan negara pengimpor telah mempersyaratkan DOBI sebagai syarat mutu CPO. Makalah ini meneliti tentang DOBI, hubungan DOBI terhadap parameter mutu CPO dan faktor-faktor yang mempengaruhi DOBI. Data sekunder nilai DOBI CPO diperoleh dari beberapa sumber referensi dari negara penghasil CPO yaitu Indonesia dan Malaysia. Hasil penelitian menunjukkan bahwa rata-rata nilai DOBI pada CPO Indonesia masih relatif rendah $(<2)$. Kadar air memiliki pengaruh terhadap nilai DOBI. DOBI memiliki korelasi searah dan kuat dengan kadar karoten namun berlawanan dan lemah terhadap ALB. DOBI sangat dipengaruhi oleh kematangan dan waktu pengolahan buah serta tahapan proses pengolahan di pabrik yang disebabkan oleh pemanasan berlebih dan kontaminasi. DOBI penting dalam perdagangan CPO sehingga parameter ini perlu ditetapkan dalam SNI CPO. Berdasarkan hasil penelitian mutu CPO Indonesia dan beberapa standar diusulkan nilai DOBI CPO pada SNI minimum 2,2. Penetapan standar ini dapat mendorong produsen untuk berupaya memperbaiki dan meningkatkan mutu CPO agar berdaya saing tinggi.
\end{abstract}

Kata kunci : crude palm oil, deterioration of bleachability index, bleaching, SNI 01-2901-2006.

\begin{abstract}
The standard of Crude Palm Oil (CPO) quality in SNI 01-2901-2006 are free fatty acid content (FFA), moisture and impurities maximum of $5 \%, 0.25 \%$ and $0.25 \%$, respectively. The other parameter which can determining the quality of CPO is deterioration of bleachability index (DOBI), but it's not be appointed in SNI of CPO. While, some of refinery industry in Indonesia and importing country have requiring $D O B I$ as quality standard of CPO. This paper research about $D O B I$, the correlation of $D O B I$ with other quality parameter of $C P O$ and factors that affecting of $D O B I$. The secondary datas of $D O B I$ of $C P O$ were obtained from some reference in the country that produce $C P O$ i.e. Indonesia and Malaysia. The result showed that DOBI of Indonesian CPO still low relatively $(<2)$. Moisture had effect to $D O B I$. DOBI had comparable and strong correlation with carotene content but contrast and weak with FFA. DOBI was very effected by maturity, time of palm fruit milling and stage of process in palm oil mill which was due to over heating and contamination. The importance of DOBI in CPO trade cause this parameter need for appointed in SNI of CPO. Refer from the research of quality of Indonesian CPO before and some of standard recommended of DOBI of CPO in SNI minimum of 2.2. This standard can triger the production for serious efforts to improve and increase the quality of CPO in order to high competitiveness.
\end{abstract}

Keywords: crude palm oil, deterioration of bleachability index, bleaching, SNI 01-2901-2006.

\section{PENDAHULUAN}

Crude palm oil (CPO) merupakan minyak yang disintesis di dalam buah sawit hingga berumur 22-24 minggu setelah pembuahan. CPO diekstraksi dari bagian mesokarp buah sawit secara mekanis dan fisika di pabrik kelapa sawit
(PKS). Banyaknya jumlah ataupun tingginya mutu CPO sangat dipengaruhi dari jenis dan kematangan buah yang diolah (Lubis, 2008; Basiron et al., 2000). Secara visual, CPO mudah dikenali dengan warna orange kemerahan karena kandungan karoten yang tinggi berkisar antara 500-700 ppm. Selain itu, pada temperatur ruang, wujudnya semi padat dengan 2 fraksi 
yaitu fraksi cair dan padat yang disebabkan oleh trigliseridanya mengandung komponen utama asam palmitat dan oleat dengan komposisi yang berimbang (Gibon et al., 2007; Hasibuan, 2012; dan Hasibuan, dkk., 2012).

Tahun 2013, total produksi CPO dunia meningkat menjadi 58,4 juta ton dari 30 juta ton pada 2004 (USDA, 2014). Dari total tersebut, sekitar 31 juta ton dikontribusikan oleh Indonesia. Selain sebagai negara produsen terbesar, Indonesia juga menempati posisi teratas sebagai negara pengekspor CPO di dunia setelah Malaysia. CPO Indonesia telah diekspor ke beberapa negara di Asia, Amerika, dan Eropa. Oleh sebab itu, sebagai produk unggulan perkebunan, komoditas ini telah memberikan devisa negara terbesar selain migas (Ditjenbun, 2014 dan Arisanti, 2014).

Perdagangan CPO baik untuk tujuan domestik maupun ekspor disesuaikan dengan persyaratan mutunya. Indonesia memiliki standar nasional untuk CPO yaitu SNI 01-2901-2006 yang mempersyaratkan kadar asam lemak bebas (ALB), air dan kotoran masing-masing maksimum 5\%, 0,25\% dan 0,25\% (BSN, 2006). Selain ketiga parameter tersebut, ada parameter lain yang dapat menentukan baik atau buruknya mutu CPO yaitu deterioration of bleachability index (DOBI). Walaupun belum menjadi suatu ketetapan dalam SNI CPO, parameter ini telah digunakan oleh beberapa perusahaan di Indonesia dan pembeli (buyer) dari negara pengimpor.

Nilai DOBI merupakan indeks daya pemucatan CPO yang berguna pada proses rafinasi untuk menentukan jumlah bleaching earth yang digunakan dan waktu proses pengolahannya. Selain itu, DOBI juga dapat menjadi salah satu parameter untuk mengukur tingkat kerusakan minyak yang disebabkan oleh oksidasi. Rendahnya nilai DOBI mengindikasikan naiknya kandungan produk oksidasi sekunder (Lin, 2004; Siahaan, 2006; dan Ng dalam Jusoh, et al., 2013).

Menurut Lin (2004) bahwa CPO yang bermutu baik apabila nilai DOBI-nya minimum 2,31 . Hasil kajian yang pernah dilakukan oleh Pusat Penelitian Kelapa Sawit (PPKS) menunjukkan bahwa rata-rata nilai DOBI CPO Indonesia relatif rendah yaitu kurang dari 2 (dengan kisaran 0,4-2,9) (Siahaan, dkk., 2009 dan Hasibuan, 2012). Nilai DOBI pada CPO Indonesia dapat ditingkatkan dengan memperbaiki beberapa faktor khususnya pengolahan buah hingga CPO. Faktor lainnya yang terpenting adalah penetapan nilai DOBI sebagai salah satu syarat mutu CPO dalam SNI
01-2901-2006. Dengan demikian, produsen akan berupaya untuk menghasilkan CPO sesuai dengan standar yang telah ditetapkan. Makalah ini menyajikan informasi tentang DOBI pada $\mathrm{CPO}$, hubungan DOBI terhadap parameter mutu $\mathrm{CPO}$, dan faktor-faktor yang mempengaruhi DOBI.

Tulisan ini diharapkan dapat memberikan informasi tentang nilai DOBI pada CPO dan faktor-faktor yang mempengaruhinya. Selain itu, tulisan ini dapat menjadi dasar (acuan) dalam penetapan nilai DOBI pada SNI CPO (SNI 012901-2006). Untuk mencapai tujuan tersebut, metode dalam melaksanakan penelitian ini dengan desk study yaitu mempelajari berbagai pustaka dan sumber referensi standardisasi nilai DOBI pada CPO di negara-negara terbesar penghasil CPO dunia, diantaranya Indonesia dan Malaysia.

\section{TINJAUAN PUSTAKA}

Buah sawit menghasilkan produk utama berupa crude palm oil (CPO) yang diperoleh dari bagian mesokarp buah yang dihasilkan di pabrik kelapa sawit (PKS) (Basiron et al., 2000 dan Lubis, 2008). Mutu CPO sangat dipengaruhi oleh faktor kebun dan faktor pengolahan di PKS. Faktor kebun diantaranya adalah kematangan buah yang dipanen dan waktu pengiriman buah ke PKS (Hasibuan \& Nuryanto, 2015). Buah sawit yang dipanen sebaiknya diolah langsung di PKS agar mutu CPO tinggi namun karena kondisi di lapangan seperti infrastruktur yang tidak baik dan curah hujan tinggi menyebabkan buah menjadi restan. Sedangkan, faktor di PKS adalah waktu, temperatur di sterilisasi dan digester dan tekanan di stasiun press-an (Owolarafe, et al., 2008; Jusoh, et al., 2013; dan Adetola, et al., 2014).

Mutu CPO sesuai SNI 01-2901-2006 masih didasarkan pada 3 parameter yaitu kadar asam lemak bebas, air dan kotoran. Sementara itu, Malaysia telah menetapkan nilai deterioration of bleachability index (DOBI) menjadi suatu ketetapan mutu CPO.

Nilai DOBI merupakan indeks daya pemucatan CPO yang berguna pada proses rafinasi untuk menentukan jumlah bleaching earth yang digunakan dan waktu proses pengolahannya. Selain itu, DOBI juga dapat menjadi salah satu parameter untuk mengukur tingkat kerusakan minyak yang disebabkan oleh oksidasi. Rendahnya nilai DOBI mengindikasikan naiknya kandungan produk oksidasi sekunder (Lin, 2004; Siahaan, 2006; dan Ng dalam Jusoh, et al., 2013). 


\section{METODE PENELITIAN}

Metode yang digunakan dalam penelitian untuk menyusun makalah ini dilakukan dengan desk study yaitu mempelajari berbagai pustaka dan sumber referensi standardisasi nilai DOBI pada CPO di negara-negara terbesar penghasil CPO dunia diantaranya adalah Indonesia dan Malaysia. Hal-hal yang diteliti diantaranya adalah informasi tentang DOBI pada CPO, hubungan DOBI terhadap parameter mutu CPO, dan faktorfaktor yang mempengaruhi DOBI.

\section{HASIL DAN PEMBAHASAN}

\subsection{Analisa Nilai DOBI pada CPO}

Penentuan nilai DOBI pada CPO tidak sulit namun untuk mendukung analisa tersebut, laboratorium mutu harus dilengkapi dengan alat spektrofotometer. Analisa nilai DOBI dapat dilakukan secara sekaligus (bersamaan) dengan penentuan kadar karoten. Kadar karoten ditentukan pada panjang gelombang $446 \mathrm{~nm}$ sedangkan DOBI pada panjang gelombang 446 $\mathrm{nm}$ dan $269 \mathrm{~nm}$. Metode penentuan keduanya cukup mudah dan sederhana sehingga dapat diterapkan oleh produsen CPO (Hasibuan, 2012).

Analisa DOBI dapat dilakukan dengan mengacu pada metode standar dan salah satunya adalah MPOB Test Method p.2.9. part 2:2004 (MPOB, 2004). Sebanyak 0,1 g CPO yang telah dicairkan dimasukkan ke dalam labu ukur $25 \mathrm{~mL}$. Ke dalam labu ditambahkan isooktan atau heksan hingga tanda garis batas. Selanjutnya campuran dimasukkan ke dalam kuvet dan dibaca absorbansinya pada $\lambda=269$ $\mathrm{nm}$ dan $\lambda=446 \mathrm{~nm}$ menggunakan alat spektrofotometer. Kadar karoten dan DOBI dihitung sesuai dengan persamaan 1 dan 2.

Kadar karoten $=\frac{25 \times A \times 383}{w \times 100}$

dan $\mathrm{DOBI}=\frac{\text { Absorbance } \lambda=446 \mathrm{~nm}}{\text { Absorbance } \lambda=269 \mathrm{~nm}}$

Keterangan:

$A=$ absorbansi $446 \mathrm{~nm}$ dan $\mathrm{w}=$ berat contoh $(\mathrm{g})$ (MPOB, 2004).

\subsection{Nilai DOBI pada Proses Bleaching}

Bleaching merupakan salah satu tahapan pada proses rafinasi yang berguna untuk menghilangkan substansi yang tidak diinginkan berupa residu sabun, logam berat, senyawa fosfat dan warna seperti pewarna karoten dan klorofil. Pada tahapan ini, nilai DOBI penting dalam keberhasilan proses bleaching dan rafinasi. Faktor-faktor yang mempengaruhi proses bleaching adalah dosis bleaching earth, temperatur dan waktu proses (Basiron et al., 2000 dan Morad, et al., 2006).

Banyak atau sedikitnya dosis bleaching earth yang digunakan sangat tergantung pada nilai DOBI. Menurut Gibon, et al. (2007) bahwa semakin rendah nilai $\mathrm{DOBI}$ maka proses pemucatan semakin sulit dan penggunaan bleaching earth semakin banyak sehingga biaya produksi tinggi. Selain itu, apabila dosis bleaching earth kurang mampu memucatkan CPO maka proses deodorisasi yang merupakan tahapan lanjutan dari bleaching menjadi terkendala. Dosis bleaching earth yang biasa digunakan berkisar antara 0,5-2,0\% dari berat CPO dan umumnya $1 \%$. Semakin tinggi dosisnya maka warna CPO lebih cepat menurun dan kadar logam berat semakin rendah. Jenisjenis bleaching earth yang sering digunakan adalah lempung terpilar, bentonit, karbon aktif, alumina, silika, dan lain-lain (Basiron, et al., 2000; Nursulihatimarsyila, et al., 2012 dan Ejikeme, et al., 2013).

Temperatur proses pada saat bleaching berpengaruh dalam pemucatan warna $\mathrm{CPO}$ dan suhu optimum yang digunakan adalah $90-105^{\circ} \mathrm{C}$. Selain temperatur, waktu bleaching juga mempengaruhi warna dan kadar ALB CPO. Sementara itu, bilangan peroksida awalnya menurun hingga 30 menit namun kemudian meningkat sejalan dengan meningkatnya waktu proses. Dengan demikian, waktu bleaching optimum adalah 30 menit (Morad, et al., 2006).

\subsection{Nilai DOBI pada CPO Indonesia}

Meskipun nilai DOBI belum menjadi syarat mutu pada CPO namun beberapa perusahaan telah menggunakan DOBI untuk perdagangan domestik dan ekspor. Beberapa peneliti telah menentukan nilai DOBI pada CPO yang dihasilkan oleh pabrik kelapa sawit (PKS) di Indonesia. Siahaan, dkk. (2009) melaporkan bahwa rata-rata nilai DOBI pada CPO Indonesia sebesar 2,24 dengan kisaran 0,9-2,99. Dari 178 PKS yang disurvei, sebanyak $17 \%$ menghasilkan $\mathrm{CPO}$ dengan nilai $\mathrm{DOBI}<2,67 \%$, nilai $\mathrm{DOBI} 2-$ 2,5 dan $16 \%$, dan nilai $\mathrm{DOBI}>2,5$. Sinaga (2011) melaporkan bahwa nilai DOBI pada CPO yang pernah dianalisa berkisar antara 1,34-3,11. Selanjutnya Hasibuan (2012) melaporkan nilai DOBI pada 205 sampel CPO yang dihasilkan oleh PKS di Indonesia memiliki rata-rata nilai 
DOBI sebesar 1,83 dengan kisaran 0,44-2,87. Dari data yang dilaporkan tersebut menunjukkan bahwa CPO Indonesia memiliki variasi nilai $\mathrm{DOBI}$ yang sangat lebar.

\subsection{Korelasi Nilai DOBI terhadap Parameter Mutu Lain CPO}

Nilai DOBI tinggi akan diperoleh jika buah yang diolah di PKS adalah buah tepat matang, karena kadar karoten yang dikandungnya juga tinggi. Pada buah mentah nilai DOBI rendah karena kadar karoten juga rendah sedangkan pada buah lewat matang nilai DOBI rendah karena kadar ALB tinggi (Gee, 1999). Basiron, et al. (2000) dan Hasibuan \& Harjanto (2009) melaporkan bahwa kadar karoten pada CPO sangat tergantung pada bahan tanaman dan dipengaruhi oleh pengolahan di PKS karena karoten mudah terdegradasi oleh panas.

Dari uraian di atas menunjukkan bahwa nilai DOBI memiliki hubungan dengan parameter mutu lain dari CPO. Frank, et al. (2013) dan Ohimain, et al. (2013) menyatakan bahwa kadar air tinggi dapat menyebabkan terjadinya reaksi deterioration sehingga kualitas CPO menjadi rendah dengan bilangan peroksida tinggi dan berbau tengik. Hasibuan, dkk. (2015) menyatakan bahwa CPO berkadar ALB tinggi cenderung memiliki nilai $\mathrm{DOBI}$ rendah namun koefisien korelasi ( $r$ ) antara keduanya rendah sebesar $-0,26$ (Gambar 1). Hal yang sama juga telah dilaporkan oleh Lin (2004) bahwa CPO berkadar ALB tinggi mempunyai nilai DOBI rendah. Rendahnya korelasi antara kadar ALB dengan nilai DOBI disebabkan oleh ALB, merupakan asam lemah dan kadarnya relatif rendah dengan kisaran 1,3-7,0\% sehingga kurang kuat mengoksidasi karoten (Hasibuan, dkk., 2015).

Hasibuan, dkk. (2015) juga menyatakan bahwa kadar karoten tinggi maka nilai DOBI cenderung tinggi. Hubungan antara keduanya sebanding atau searah dan kuat dengan koefisien korelasi ( $r$ ) sebesar 0,82 (Gambar 2). Tingginya nilai korelasi antara keduanya disebabkan oleh nilai DOBI, merupakan perbandingan antara kadar karoten dengan produk teroksidasinya. Apabila produk teroksidasi dari karoten rendah maka nilai DOBI tinggi (Lin, 2004 dan Jusoh, dkk., 2013).

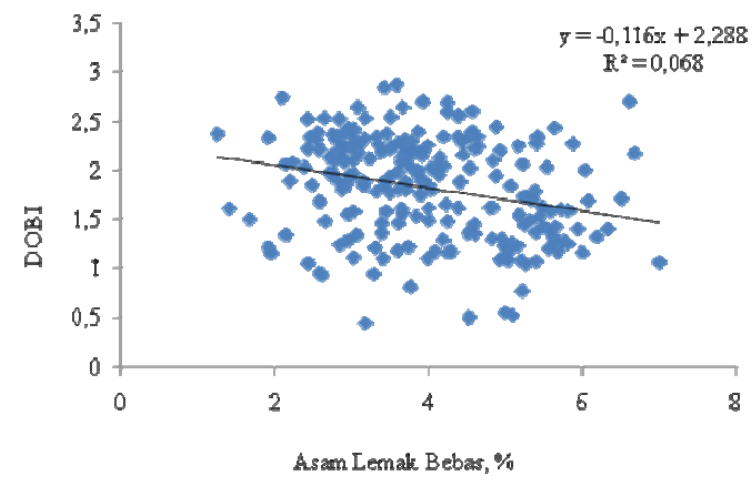

Gambar 1. Korelasi antara kadar ALB dan nilai DOBI.

(sumber: Hasibuan, dkk., 2015).

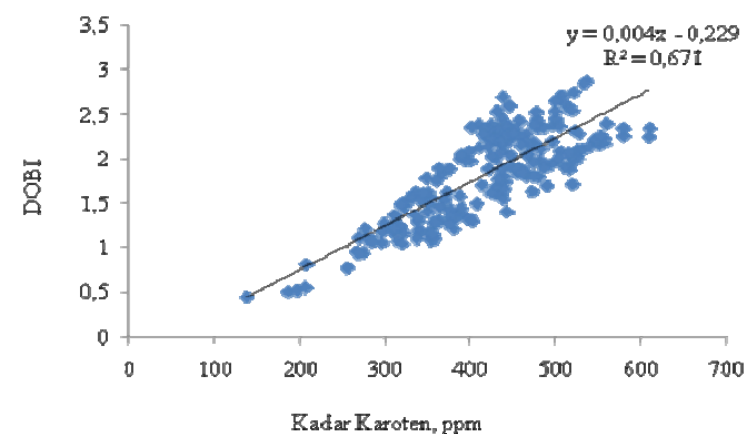

Gambar 2. Korelasi antara kadar karoten dan DOBI

(sumber: Hasibuan, dkk., 2015).

\subsection{Faktor-Faktor Yang Mempengaruhi Nilai DOBI}

Rendahnya nilai DOBI pada CPO dapat disebabkan oleh beberapa faktor khususnya pada pengolahan buah dan minyak. Pada proses pengolahan yang perlu diperhatikan adalah kematangan buah, waktu pengolahan buah, kondisi proses pengolahan, kontaminasi CPO, penyimpanan, dan distribusi CPO (Gee, 1999 dan Jusoh, dkk., 2013).

\subsubsection{Kematangan Buah}

Buah sawit yang diolah di pabrik kelapa sawit (PKS) sebaiknya dengan kematangan optimum yaitu tepat matang. Hal ini dipersyaratkan agar diperoleh rendemen CPO yang tinggi. Selain itu, mutu CPO yang dihasilkan juga sesuai dengan standar (Lubis, 2008 dan Panjaitan, dkk., 2009). Namun, beberapa praktek di lapangan memperlihatkan bahwa buah mentah dan buah lewat matang masih dipanen dan diolah di PKS.

Nilai DOBI pada buah mentah berkisar antara $2,45-4,13$, buah matang $0,99-2,96$, buah lewat matang 2,53-6,69 dan berondolan 2,192,54 (Jusoh, et al., 2013). Sementara itu, 
Hasibuan (2015) melaporkan bahwa buah mentah memiliki nilai DOBI sebesar 4,1 (2,9$4,9)$, buah matang $4,3(3,9-4,8)$ dan buah lewat matang 3,9 (3,1-4,5). Dari data yang disajikan tersebut menunjukkan bahwa kematangan buah sangat mempengaruhi nilai DOBI. Tingkat kematangan buah ini berkaitan dengan warna buah dan kadar karoten yang dikandungnya. Gambar 3 menunjukkan bahwa buah matang dan lewat matang berwarna merah sementara buah mentah berwarna hitam kemerahan.

Karoten tersintesis di dalam buah secara alamiah sejak proses pembuahan hingga panen berumur 22-24 minggu (Basiron, et al., 2000). Menurut Siahaan, dkk. (2006) bahwa buah mentah cenderung memiliki kadar karoten yang rendah dibandingkan buah matang dan lewat matang. Selama pengolahan, CPO yang kontak dengan panas dan cahaya yang berlebihan menyebabkan karoten terdegradasi sehingga kadarnya menjadi rendah dan berdampak pada nilai DOBI juga rendah (Panjaitan, dkk., 2009 dan Hasibuan \& Ramadona, 2012). Hasibuan, dkk. (2015) menyatakan bahwa kadar karoten memiliki hubungan yang erat dan sebanding dengan nilai DOBI.

\subsubsection{Penundaan Waktu Pengolahan Buah}

Rendahnya nilai DOBI pada CPO juga dapat disebabkan oleh tertundanya pengolahan buah sawit. Penundaan ini dapat terjadi karena buah tidak segera diangkut ke PKS (buah menginap/restan) yang disebabkan oleh infrastruktur yang buruk dan musim hujan, proses di PKS terhenti karena adanya kerusakan peralatan dan buah yang diterima berlebih dari kapasitas olah (Gee, 1999). Hasibuan (2015) menyatakan bahwa penundaan waktu pengolahan buah sawit menyebabkan nilai DOBI menurun (Gambar 4). Dari Gambar 4 menunjukkan bahwa penurunan nilai DOBI cenderung lebih tinggi pada buah lewat matang dibandingkan buah matang dan mentah selama 72 jam.

\subsubsection{Pengolahan Buah di PKS}

Degradasi CPO dapat terjadi pada beberapa tahapan proses yang secara konsekuen mempengaruhi kualitasnya termasuk nilai DOBI (Hamdan, et al., 2015). Panjaitan, dkk. (2009) melaporkan bahwa nilai DOBI pada CPO di 3 PKS menurun dari 3,0 di stasiun sterilisasi menjadi 2,5 di stasiun vacuum drying dengan persentasi penurunan sebesar $12-22 \%$. Halim \& Ah (2004) juga menyatakan hal yang sama bahwa mutu CPO di setiap unit proses baik kadar karoten dan nilai DOBI semakin rendah sebaliknya kadar ALB semakin tinggi. Titik kritis penurunan nilai DOBI terjadi pada stasiun sterilisasi. Pada tahapan ini, secara umum waktu pemanasan buah yang dibutuhkan selama 90 menit dengan interval suhu $130-150{ }^{\circ} \mathrm{C}$. Waktu sterilisasi memiliki pengaruh yang lebih besar dibandingkan temperatur terhadap nilai DOBI (Akmazillah, et al., 2011; Subramaniam, et al., 2013; dan Jusoh, et al., 2013).

Setelah proses sterilisasi tahapan selanjutnya adalah oil gutter, crude oil tank, oil tank, purifier, dan vacuum dryer. Pada tahapantahapan tersebut CPO mengalami pemanasan pada suhu $90-95{ }^{\circ} \mathrm{C}$. Kurangnya pengawasan menimbulkan suhu di unit proses tidak terkontrol sehingga mencapai lebih dari $95^{\circ} \mathrm{C}$. Tingginya suhu dan lamanya pemanasan menyebabkan karoten terdegradasi dan nilai DOBI menurun karena minyak teroksidasi (PORIM, 1987). Sebagai pembanding, Hadi, et al. (2012) melaporkan bahwa nilai DOBI pada CPO yang dihasilkan dengan cara ekstraksi menggunakan heksan berkisar antara 4,19-6,72. Nilai ini lebih tinggi dibandingkan pada CPO yang dihasilkan dengan metode perebusan seperti yang telah dilaporkan oleh Halim \& Ah (2004), Panjaitan, dkk. (2009), Siahaan, dkk. (2009), Sinaga (2011), dan Hasibuan (2012).
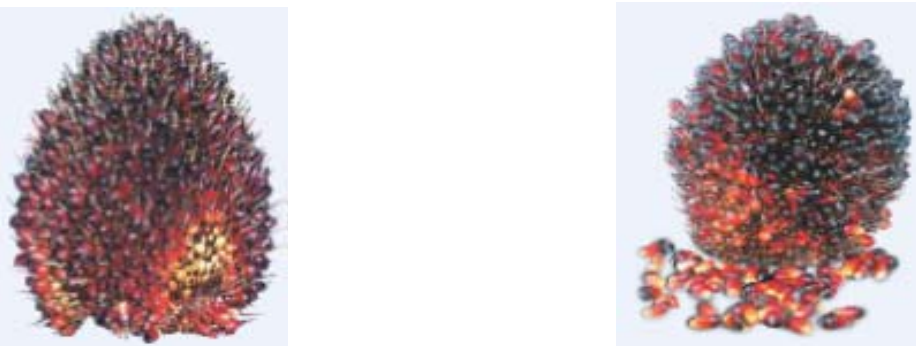

Gambar 3 Buah mentah (kiri), matang (tengah) dan lewat matang (kanan).

(Sumber: Foto PPKS) 


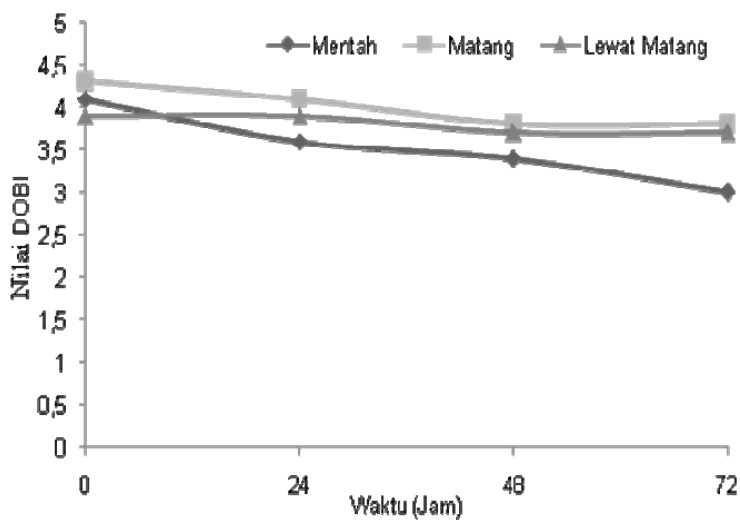

Gambar 4 Penurunan nilai DOBI pada CPO selama penundaan pengolahan.

(sumber: Hasibuan, 2015)

\subsubsection{Kontaminasi CPO}

Mutu CPO akan menurun apabila terjadi kontaminasi oleh kondensat di unit sterilizer, injeksi steam dan panas di unit digestion, tekanan tinggi di unit press, oksidasi minyak di unit klarifikasi, dan pemanasan yang berlebih di tangki timbun (Hamdan, et al., 2015). Selain itu, pengutipan kembali (recovery) CPO dari produk samping juga dapat menimbulkan kontaminasi apabila mutunya rendah yang dicampurkan ke dalam CPO bermutu tinggi. CPO yang dikutip umumnya berasal dari air kondensat, sludge, empty fruit bunch dan serat (fiber). Wafthi, et al. (2012) menyatakan bahwa minyak dari sludge mengandung ALB berkisar antara 40-80\%, berwarna gelap, berbau dan berbentuk padat pada temperatur $25^{\circ} \mathrm{C}$.

Sementara itu, minyak dari produk samping bermutu baik dapat dicampurkan dengan CPO yang sesuai dengan standar proses. Seperti yang telah dilaporkan oleh Subramaniam, et al. (2013), CPO yang dihasilkan dari serat mengandung nilai DOBI sebesar 2,8-3,0 dengan kadar karoten 14001600 ppm dan asam lemak bebas 3,33-4,85\%. Yunos, et al. (2015) melaporkan bahwa nilai DOBI pada spikelet dan stalk sebesar 2,43 dan pada fiber 2,42 sementara pada CPO 2,45.
Praktek recovery ini sering dilakukan oleh beberapa perusahaan agar diperoleh rendemen yang tinggi untuk memenuhi target. Yudanto (2005) melaporkan sebanyak 0,23 ton per hari, minyak dapat diekstrak dari berondolan yang tidak terkutip di tandan kosong sawit pada PKS kapasitas 5 ton TBS/jam. Lau, et al. (2006) menyatakan bahwa minyak yang dapat diekstrak dari serat sebanyak 5-6\%. Yunos, et al. (2015) menyatakan bahwa minyak yang dapat dikutip dari spikelet, stalk dan serat masing-masing sebesar $7,39 \pm 3,45 \%, \quad 2,04 \pm 2,41 \%$, dan $3,61 \pm 0,34 \%$.

Onwuka \& Akaerue (2006) juga menyatakan bahwa kontaminasi logam berat dari peralatan proses khususnya tembaga dan besi yang dikategorikan sebagai pro-oksidan kuat juga dapat terjadi dan menyebabkan nilai DOBI menurun. Tidak hanya di PKS, kontaminasi juga dapat terjadi selama transportasi CPO dari PKS ke industri rafinasi (Perumal, 2009). Kontaminasi ini terjadi karena tangki tidak bersih dan atau sengaja dicampur dengan air atau bahan-bahan lainnya. CPO juga dapat terkontaminasi oleh minyak non nabati seperti petroleum, castor oil dan solar. Kontaminasi ini pernah terjadi pada Oktober 1999, sebanyak 85.000 metrik ton CPO yang dikembalikan karena terkontaminasi solar selama proses pengiriman dari Indonesia ke Belanda yang disebabkan oleh tidak bersinnya tangki (Data Consult dalam Fizura, et al., 2014).

\subsubsection{Pemanasan CPO Berlebihan di Tangki Timbun}

CPO yang dihasilkan akan dikumpulkan di dalam tangki penyimpanan (storage tank). Biasanya, suhu di tangki timbun selalu dikontrol dan pemanasannya tidak melebihi dari $55{ }^{\circ} \mathrm{C}$. Penyimpanan pada waktu yang lama dengan mengaplikasikan panas akan menyebabkan nilai DOBI menurun. Hasibuan \& Ramadona (2012) melaporkan pengaruh waktu penyimpanan $\mathrm{CPO}$ terhadap nilai DOBI pada suhu $50^{\circ} \mathrm{C}, 60^{\circ} \mathrm{C}$, dan $70{ }^{\circ} \mathrm{C}$ (Tabel 1). Semakin tinggi suhu dan lama penyimpanan menyebabkan nilai $\mathrm{DOBI}$ semakin menurun secara drastis.

Tabel 1 Penurunan nilai DOBI selama penyimpanan.

\begin{tabular}{|c|c|c|c|c|c|c|c|c|c|c|c|c|}
\hline \multirow{2}{*}{$\begin{array}{c}\text { LEVEL } \\
\text { ALB/KAROTEN/DOBI } \\
\text { Suhu Penyimpanan } \\
\end{array}$} & \multicolumn{3}{|c|}{$2,68 \% / 453 \mathrm{ppm} / 2$, } & \multicolumn{3}{|c|}{$5,11 \% / 452 \mathrm{ppm} / 2,21$} & \multicolumn{3}{|c|}{$10,01 \% / 437$ ppm/1,55 } & \multicolumn{3}{|c|}{$24,24 \% / 346$ ppm/0,64 } \\
\hline & $50^{\circ} \mathrm{C}$ & $60^{\circ} \mathrm{C}$ & $70^{\circ} \mathrm{C}$ & $50^{\circ} \mathrm{C}$ & $60^{\circ} \mathrm{C}$ & $70^{\circ} \mathrm{C}$ & $50^{\circ} \mathrm{C}$ & $60^{\circ} \mathrm{C}$ & $70^{\circ} \mathrm{C}$ & $50^{\circ} \mathrm{C}$ & $60^{\circ} \mathrm{C}$ & $70^{\circ} \mathrm{C}$ \\
\hline$\%$ Penurunan DOBI, 1 hari & 3,82 & 5,15 & 12,7 & 3,94 & 7,18 & 14,22 & 2,36 & 6,03 & 13,33 & 7,69 & 8,89 & 21,43 \\
\hline$\%$ Penurunan DOBI, 3 hari & 3,18 & 14,16 & 18,03 & 5,51 & 17,7 & 24,77 & 7,09 & 17,09 & 20,95 & 15,38 & 46,67 & 50 \\
\hline$\%$ Penurunan DOBI, 7 hari & 13,82 & 33,95 & 56,8 & 17,64 & 40,19 & 69,68 & 16,54 & 39,4 & 64 & 37,69 & 88,67 & 100 \\
\hline
\end{tabular}


Nilai DOBI yang rendah $(0,64)$ pada CPO dengan pemanasan yang tinggi $>50{ }^{\circ} \mathrm{C}$ menyebabkan CPO menjadi berwarna cokelat dan nilai DOBI-nya nol.

\subsubsection{Standardisasi Nilai DOBI pada SNI CPO (SNI 01-2901-2006)}

Negara Malaysia sebagai salah satu kompetitor telah mempersyaratkan nilai DOBI selain kadar ALB, air dan kotoran sebagai standar mutu dengan nilai minimum 2,8 (CPO grade spesial), 2,5 (CPO grade I) dan 2,2 (CPO grade II) (Malaysian Standard/MS 814-2007). Hal ini bersesuaian dengan nilai $\mathrm{DOBI}$ sebesar 1,782,30 disebut sebagai CPO berkualitas rendah, 2,31-2,92 berkualitas cukup baik, 2,93-3,24 berkualitas baik dan di atas 3,24 berkualitas sangat baik (Lin, 2004; Hadi, et al., 2012; dan Jusoh, et al., 2013). Selain Malaysia, beberapa perusahaan di Indonesia juga telah menggunakan nilai $\mathrm{DOBI}$ dalam perdagangan CPO Indonesia baik di dalam maupun luar negeri. Bursa Komoditi dan Derifatif Indonesia (Indonesia Commodity and Derivatives
Exchange, ICDX) dalam spesifikasi kontrak berjangka CPO menetapkan nilai DOBI saat penyerahaan minimum 2,1 (ICDX, 2009).

Sebagai negara produsen dan pengekspor CPO terbesar di dunia, Indonesia pun harus meningkatkan daya saing dengan menetapkan nilai DOBI sebagai standar mutu dalam SNI CPO (SNI 01-2901-2006). Hal ini dilakukan agar pelaku industri berupaya untuk menghasilkan CPO dengan nilai DOBI sesuai dengan standar mutu yang ditetapkan secara nasional. Untuk itu, sebagai suatu standar, direkomendasikan nilai $\mathrm{DOBI}$ pada SNI CPO Indonesia minimum sebesar 2,2 (Tabel 2). Nilai ini telah disesuaikan dengan mempertimbangkan kadar ALB pada SNI dengan 1 kelas saja yaitu maksimum sebesar $5 \%$. Sementara itu, negara Malaysia mempersyaratkan nilai DOBI pada 3 kelas sesuai kadar ALB yang dikandungnya. Nilai DOBI dan kadar ALB pada CPO grade spesial sebesar 2,8 (2,5\%), grade । 2,5 (3,5\%) dan grade II 2,2 (5,0\%) (MS dalam Gibon, et al., 2007).

Tabel 2 Usulan SNI CPO sebagai revisi SNI 01-2901-2006.

\begin{tabular}{lccc}
\hline \multicolumn{1}{c}{ Parameter } & Persyaratan & Satuan & Acuan \\
\hline Kadar asam lemak bebas & 5,0 & $\%$ & \\
kadar air & 0,45 & $\%$ & SNI-01-2901-2006 \\
Kadar kotoan & 0,05 & $\%$ & Usulan baru (referensi: \\
nilai DOBI & 2,2 & & $1,2,3,4)$ \\
\hline
\end{tabular}

(Sumber: Gibon, et al., 2007; Lin, 2004; Hadi, et al., 2012; dan Jusoh, et al., 2013)

Berdasarkan laporan Siahaan, dkk. (2009) bahwa sekitar $98 \%$ dari 178 PKS di Indonesia menghasilkan CPO berkadar ALB $<5 \%$. Hal yang sama dilaporkan oleh Hasibuan (2012) bahwa dari 205 sampel CPO di Indonesia memiliki kadar ALB rata-rata 3,94\% (1,3-7,0\%). Dengan demikian, usulan standar nilai DOBI pada SNI 01-2901-2006 sebesar 2,2 akan dapat terpenuhi oleh PKS di Indonesia. Untuk memenuhi standar tersebut, pelaku industri harus mempertimbangkan faktor-faktor yang dapat mempengaruhi tinggi rendahnya nilai DOBI baik saat pengolahan buah sawit hingga CPO.

\section{KESIMPULAN}

Berdasarkan uraian di atas disimpulkan bahwa nilai deterioration of bleachability index (DOBI) telah menjadi salah satu tolok ukur mutu CPO di perdagangan lokal dan ekspor. Nilai DOBI dapat digunakan untuk menentukan mutu CPO dan kerusakannya akibat oksidasi. Parameter ini juga digunakan sebagai dasar dalam penggunaan dosis bleaching earth saat proses bleaching dalam rafinasi CPO menjadi produk intermediate maupun bahan jadi seperti minyak goreng.

Nilai DOBI yang dihasilkan oleh beberapa pabrik kelapa sawit (PKS) di Indonesia masih relatif rendah $(<2)$. Untuk meningkatkan daya saing CPO Indonesia diperlukan peningkatan mutu dan salah satunya adalah dengan meningkatkan syarat mutu CPO pada SNI 012901-2006. Oleh sebab itu, diusulkan DOBI sebagai standar mutu CPO pada SNI dengan nilai minimum 2,2. Usulan standar nilai DOBI ini didasarkan pada kadar asam lemak bebas (ALB) pada SNI hanya 1 yaitu maksimum $5 \%$. Standar ini akan terpenuhi oleh pelaku industri apabila mempertimbangkan faktor-faktor yang mempengaruhi nilai DOBI. CPO dengan nilai 
DOBI tinggi akan diperoleh apabila buah yang diolah di PKS dengan kematangan yang optimum, buah segera diolah dengan waktu penundaan maksimum selama 24 jam, perlakuan panas saat pengolahan tidak berlebihan, tidak terkontaminasi oleh bahan kontaminan berupa air kondensat, sludge, CPO bermutu rendah (off grade), minyak non nabati, dan pemanasan CPO saat penyimpanan dan distribusi tidak berlebih $\left(<55^{\circ} \mathrm{C}\right)$.

\section{UCAPAN TERIMA KASIH}

Penulis mengucapkan terima kasih kepada penulis yang tercantum dalam daftar pustaka karena telah menjadi referensi bagi penulis dalam penyusunan makalah ini.

\section{DAFTAR PUSTAKA}

Akhmazillah, M. F., Sarmidi, M. R., \& Chua, L. S. (2011). Metabolite profiling of heat treated whole palm oil extract. Asian Journal of Food and Agro Industry, 4, 132-140.

Arisanti, O. (2014). Studi ekspor crude palm oil (CPO) Indonesia ke Slovakia. e-Journal IImu Hubungan International, 2, 97-110.

Badan Standardisasi Nasional. (2006). SNI-012901-2006 - Minyak Kelapa Sawit Mentah (Crude Palm Oil). Jakarta: BSN

Basiron, Y., Jalani, B. S., \& Weng, C. K. (2000a). Advances Oil Palm Research. Volume I. Malaysia: Malaysian Palm Oil Board.

Basiron, Y., Jalani, B. S., \& Weng, C. K. (2000b). Advances Oil Palm Research. Volume II. Malaysia: Malaysian Palm Oil Board.

CODEX. (1999). CODEX STAN 210 - CODEX Standard for Named Vegetabel Oils.

Ditjenbun. (2014). Statistik Perkebunan Indonesia. Jakarta: Direktorat Jenderal Perkebunan. Indonesia.

Ejikeme, E. M., Egbuna, S.O., \& Ejikeme, P. C. N. (2013). Optimal bleaching performance of acid activated 'Ngwulangwu' clay. International Journal of Engineering and Innovative Technology, 3, 13-19.

Fizura, C. H., Aziz, S. A., \& Hafizan, S. (2014). Effect of diesel contamination on capacitance values of crude palm oil. Journal of Engineering Science and Technology, 9, 286-292.

Frank, N. E. G., Akbert, M. M. E., \& Astride, E. M. (2013). Some qualiity parameters of crude palm oil from major markets of
Douala, Cameroon. African Journal of Food Science, 7, 473-478.

Gee, P. T. (1999). Use of the deterioration of bleachability index (DOBI) to characterize the quality of crude palm oil. Masai, Malaysia: Retrieved from http://innoleague.com/Deterioration-OfBleachability.pdf.

Gibon, V., Greyt, W. D., \& Kellens, M. (2007). Palm oil refining. Eur. J. Lipid Sci. Technol, 109, 315-335.

Hadi, N. A., Han, N. M., May, C. Y., \& Ngan, M. A. (2012). Dry heating of palm fruits: effect on selected parameters. American Journal of Engeneering and Applied Sciences, 5, 128-131.

Halim, R. M., \& Ah, N. M. (2004). Effect of temperature on the quality fresh crude palm oil at different stages of processing. Oil Palm Buletin, 43, 31-37.

Hamdan, K., Aziz, S. A., Yahya, A., Rokhani, F. Z., \& Steward, B. L. (2015). Detection of sludge contamination in crude palm oil using dielectric spectroscopy. American Society of Agricultural and Biological Engineers, 58, 227-232.

Hasibuan, H. A., \& Harjanto, S. (2009). Kajian lanjutan kadar karoten pada CPO Indonesia. Jurnal Standardisasi, 11, 220225.

Hasibuan, H. A. (2012a). Kajian mutu dan karakteristik minyak sawit indonesia serta produk fraksinasinya. Jurnal Standardisasi, 14, 13-21.

Hasibuan, H. A. (2012b). Peran standar mutu dalam menjamin kualitas CPO. Sawit Media, 1.

Hasibuan, H. A., Siahaan, D., \& Sunarya. (2012). Kajian karakteristik minyak inti sawit indonesia dan produk fraksinya terkait dengan amandemen standar codex. Jurnal Standardisasi, 14, 98-104.

Hasibuan, H. A., \& Ramadona. (2012). Monitoring kadar asam lemak bebas (ALB), kadar karoten dan DOBI pada CPO bervariasi ALB selama penyimpanan. Warta Pusat Penelitian Kelapa Sawit, 17, 87-92.

Hasibuan, H. A. (2015). Kadar dan mutu CPO selama penundaaan waktu pengolahan buah sawit. Prosiding Pertemuan Teknis Kelapa Sawit 2015 in progress.

Hasibuan, H. A., Warnoto, Lubis, A., Magindrin, I \& Silalahi, S. (2015). Asam lemak bebas, karoten, dobi dan korelasinya pada crude 
palm oil (CPO). Prosiding Pertemuan Teknis Kelapa Sawit 2015 in progress.

Indonesian Commodity and Derivatives Exchange (ICDX). (2009). Spesifikasi kontrak berjangka CPO. Jakarta: ICDX.

Jusoh, J. M., Rashid, N. A., \& Omar, Z. (2013). Effect of sterilization process on deterioration of bleachability index (DOBI) of crude palm oil (CPO) extracted from different degree of oil palm ripeness. International Journal of Bisocience, Biochemistry and Bioinformatics, 3, 322327.

Lau, H. L. N., May, C. Y., Ma, A. N., \& Chuah, C. H. (2006). Quality of residual oil from palm-pressed mesocarp fiber (Elaeis guineensis) using supercritical $\mathrm{CO}_{2}$ with and without ethanol. Journal of American Oil Chem. Soc, 83, 893-899.

Lin, S. W. (2004). Deterioration of bleachability index. MPOB information series. MPOB TT, 253.

Lubis, A. (2008). Kelapa sawit (elaeis guinense) di Indonesia. Penerbit Pusat Penelitian Kelapa Sawit. Edisi 2.

Malaysian Standard. (2007). Standards and Industrial Research Institute of Malaysia (SIRIM). Kuala Lumpur: SIRIM

Morad, N. A., Aziz, M. K. A., \& Zin, R. M. (2006). Process design degumming and bleaching of palm oil. Research Vote, 74198.

MPOB. (2004). MPOB test method: a compendium of test on palm oil products, palm kernel products, fatty acids, food related products and others. Malaysia: MPOB

Nursulihatimarsyila, A. W., Cheah, K. Y., Chuah, T. G., Siew, W. L., \& Choong, T. S. Y. (2012). Deoiling and regeneration efficiencies of spent bleaching clay. American Journal of Applied Sciences, 7, 434-437.

Ohimain, E. I., Izah, S. C., \& Fawari, A. D. (2013). Quality assessment of crude palm oil produced by semi-mechanized processor in Bayelsa State, Nigeria. Discourse Journal of Agriculture and Food Sciences, 1, 171-181.

Onwuka, G. I., \& Akaerue, B. I. (2006). Evaluation of the quality of palm oil produced by differnet methods of processing. Research Journal of Biological Science, 1, 16-19.
Panjaitan, F. R., Siahaan, D., Rivani, M., \& Hasibuan, H. A. (2009). Perubahan mutu minyak sawit selama proses pengolahan di pabrik kelapa sawit. Prosiding Pertemuan Teknis Kelapa Sawit, 287-294.

Perumal, E. (2009). Palm oil importers reassured. Retrieved June 13, 2009 from www.thestar.com.my/story/?file $=\% 2 f 2009$ $\% 2 f 6 \%$ sf $13 \% 2$ fnation $\% 2 f 4113642 \& s e c=n$ ation.

PORIM. (1987). Palm oil factory handbook. Part 1. Kuala Lumpur: PORIM.

Siahaan, D. (2006). Laporan Tahunan 2006 Nilai DOBI CPO Indonesia. Medan: PPKS.

Siahaan, D., Johnlennon, T., \& Manik, M. (2006). Study on carotene content of palm oil in different varieties maturity and unit process in palm oil mill. Proceedings of International Oil Palm Conference 2006.

Siahaan, D., Hasibuan, H. A., Nuryanto, E., Rivani, M., \& Panjaitan, F. R. (2009). Karakteristik CPO Indonesia. Prosiding Pertemuan Teknis Kelapa Sawit 2009, 273-280.

Sinaga, R. A. (2011). Kajian mutu minyak sawit kasar dan analisis karakteristik olein serta stearin sebagai hasil fraksinasinya. Skripsi Tidak Diterbitkan. Intitut Teknologi Bogor.

Subramaniam, V., Menon, N. R., Sin, H., \& May, C.Y. (2013). The development of a residual oil recovery system to increase the revenue of a palm oil mill. Journal of Oil Palm Research, 25, 116-122.

United States Department of America. (2014). Oilseeds: world markets and trade. Circular Series FOP, 1-14.

Wafti, N. A., Nang, H. L. L., \& May, C.Y. (2012). Value-added products from palm sludge oil. Journal of Applied Sciences, 1-4.

Yudanto, B. G. (2005). Potensi peningkatan rendemen pabrik kelapa sawit melalui pemipilan ulang buah sawit di unstrip bunch menggunakan mesin empty bunch crusher. Jurnal Penelitian Kelapa Sawit, 13, 137-144.

Yunos, N. S. H. M., Baharuddin, A. S., Yunos, K. F. M., Hafid, H. S., Busu, Z. , Mokhtar, M. N., Sulaiman, A., \& Som, A. M. (2015). The physicochemical charasteristics of residual oil and fibers from oil palm emptry fruit bunches. Bioresources, 10, 14-29. 
